\title{
Tagasi Siberi Kasekülas
}

Anu Korb

\begin{abstract}
Teesid
Artiklis jälgitakse ühes u 100 aasta vanuses Siberi eesti kogukonnas (Tomski oblasti Kasekülas) viimase kümmekonna aasta jooksul toimunud muutusi. Vaadeldakse, kas ja kuidas võõrsil elav vähemusgrupp, kelle kontaktid emamaaga on viimasel aastakümnel nii majanduslikel kui ka poliitilistel põhjustel nõrgenenud, suudab oma keelelist ja kultuurilist identiteeti säilitada. Arutletakse, kuivõrd aitab Kaseküla eesti kogukonna püsimisele kaasa Vene Föderatsioonis elavate väikerahvaste eneseteadvuse üldine tõus ning eesti kogukonna entusiastide teadlik omakultuuri väärtustamine ja traditsioonide taaselustamine ning kas keerulises majandusolukorras on üldse võimalik võõrkultuuri ja enamusrahvuse keele järjest suurenevale pealetungile vastu seista.
\end{abstract}

Märksõnad: eesti kogukond, identiteet, muutused, Siber, traditsioonid

Teekond Kasekülla, minu reisikaaslaseks Villi Sulger, abiks Eesti Kultuurkapitali ja Rahvuskultuuri Fondi toetused, algas lõikuskuises suvesoojas mitmepäevase rongis loksumisega. Ülikoolilinn Tomsk võttis meid oma 400. juubelisünnipäeva eel vastu eriti värske ja värvikana. Meie sihtpunktini jäi oblastikeskusest veel ligi paarsada kilomeetrit asfaltkattega teed, parvega tuli ületada Tšulõmi jõgi.

ERA 4-liikmelise ekspeditsioonigrupiga olin Pervomaiski rajoonis asuvas Kasekülas töötanud rohkem kui 11 aastat tagasi - väheste külmakraadidega lumerohkel talvel. Vahepeal olin mitmete külaelanikega kirju vahetanud, sarja "Eesti asundused" kolmanda raamatu "Seitse küla Siberis", kus ka Kaseküla tekstid sees, valmis saanud ning mõned eksemplarid sellest ka külla saatnud. Nüüd tahtsin jälgida kümmekonna aasta jooksul ühes kogukonnas toimunud muutusi.

\section{Taustast}

Koguja-uurija prestiiž on Siberi külakogukonnas kõrge: eesti külades käinud uurijaid (nt Jüri Viikbergi, Lembit Vaba, Igor Tõnuristi, Edgar Saart) teavad paljud külaelanikud nimepidi suhteliselt pika vahemaa taha. Muidugi mäletati ka meid, 1993. aastal Kasekülas käinuid: Aado Lintropi, Kadri Peebot, Astrid Tuisku ja mind.

http://haldjas.folklore.eeltagused/nr27/korb.pdf 


\section{Anu Korb}

Küsitlemisel Siberis keskendusin eesti keele ja kultuuri kandjatele, seega põhiosas vanema põlvkonna esindajaile. Sama kogukonna teistkordseks külastuseks oli nii mõnegi hea informandi maine teekond lõppenud. Rahvuskoolid kaotati Venemaal aastail 19361938 ning vaid ühte Siberi külla - Ülem-Suetukki - on taasloodud Eesti Vabariik emakeele-õpetaja saatnud. Kuna tegemist on võõrsil elava vähemusgrupiga, kelle kontaktid emamaaga on viimasel aastakümnel eelkõige majanduslikel põhjustel nõrgenenud, on võõrkultuuri järjest suurenev pealetung paratamatu. Kolhooside-sovhooside lagunemise tagajärjed annavad Siberi külades veel kaua teravalt tunda, 60-70 aastat ühismajandielu on eraalgatust suuresti pärssinud. Kuidagi tulevad inimesed oma loomade ja aiamaa varal siiski toime. Samas kardetakse eraomandivastase kampaania (nagu see oli aastatel 1920-1930) kordumist. Majanduslikult on enamike Siberi eesti kogukondade elu viimase kümne aasta jooksul halvenenud.

\section{Kaseküla majanduselu ja olme täna}

Kasekülaski elati aastal 1993 jõukamalt kui nüüd. Endise suurmajandi jäänukina on Kasekülas praegu vähese töötajate arvuga põllumajandusühistu (сельскохозяйственный кооператив), kuid see suudab oma liikmetele maksta vaid tagasihoidlikku naturaaltasu, sedagi alles pärast sügistööde lõppu. Mõned teevad esimesi katseid iseseisvalt toime tulla: seitse meest astunud ühistust välja ning harivad nüüd põldu omapäi. Esialgu pole neilgi kerge. Küla oli oma tähtsust kaotanud ka administratiivses plaanis: kui 1993. aastal oli siin oma külanõukogu, siis aastaks 2004 oli see üle viidud naabruses asuvasse vene külla ning Kasekülas töötas vaid külanõukogu sekretär. Temalt saime teada küll Kaseküla elanike arvu -624, tollasest pisut enam, kuid mitte külas elavate eestlaste oma. Venemaa 2002. aasta rahvaloenduse andmeid külanõukogu käsutuses polevat. Aastal 1993 kosteti meie samalaadse pärimise peale rõhuga, et siin rahvuste vahel vahet ei tehta. Nüüd kuulsime, et eestlased on külas venelaste järel arvukuselt teisel kohal ning üldse elavat siin 12 eri rahvuse esindajad. Paraku olevat Tšuvaššiast mitmesuguste toetuste abil külla meelitatud elanikud, kelle järgi uusasukate uulits rahvakeelse Tšeboksarõ nime sai, pärast soodustuste kaotamist enamjaolt külast lahkunud. 


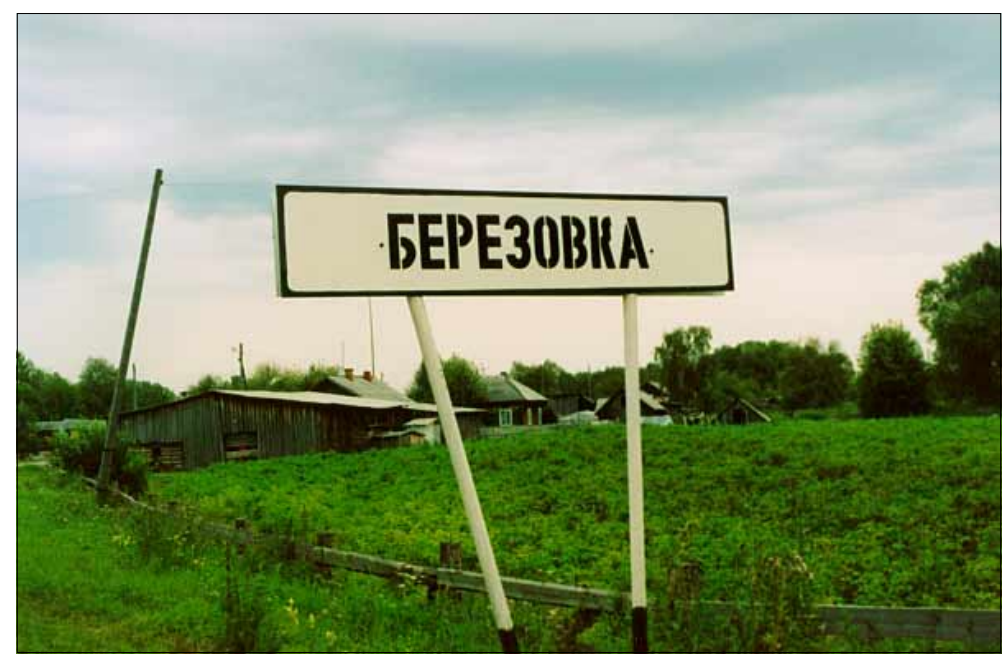

Siit algab Kaseküla. Anu Korbi foto 2004.

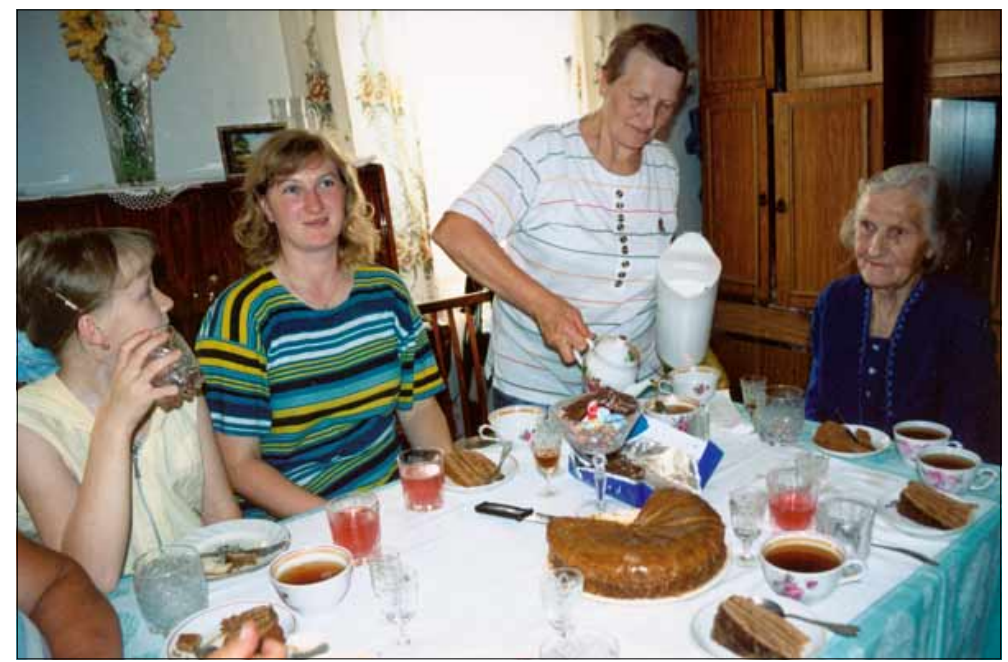

Neli põlvkonda: Maie, Alla ja Agnessa Koot ning Olga Veltmander. Anu Korbi foto 2004. 


\section{Anu Korb}

Bussiühendus rajoonikeskusega oli harvenenud: buss käis vaid kolmel päeval nädalas. Minu imestuseks kogunesid bussigraafiku järgi peatusse ka kohalikud eratranspordi pakkujad.

Kaseküla oma lillerohkuse ja puhaste uulitsate-õuedega mõjus armsalt-koduselt nagu talvise esmakülastuse ajalgi. Paraku läinud Kaseküla ilmad ilusaks vahetult enne meie külla jõudmist. Vihmaga muutuvad siinsed muldteed (niisugune viib ka heinamaadeni) põhjatuteks porimülgasteks. Heinategu oli päevakorral kogu meie külas oleku aja. Korduvalt arutleti ka Tšulõmi-äärsete luhaheinamaade saatuse üle, sest jõgi võtvat järjest maad enda alla. Traktorid pole hobust veel kõrvale tõrjuda suutnud, heinatööks sobisid ühtviisi mõlemad. Külakari käis veel pikil päevil, lõunaseks lüpsiks aeti loomad koju. Karjas tuli käia kordamööda vastavalt loomade arvule. Sääski nüüd, augustikuus, peaaegu polnud, kuid see-eest ründasid nii loomi kui meid endid arvukad kihulaste parved, õnneks sai nende eest tuppa peitu pugeda.

Meie tookordne perenaine Olga Reile oli nüüdseks rajoonikeskusse tütre juurde kolinud ning peavarju leidsime Emilia Bogensi juures. Siinses elamus jätkus lahedasti ruumi, tekstiilide hulk toasisustuses reetis osavat käsitöömeistrit. Positiivse poole pealt tuleks mainida ka perenaise mõõdutunnet meie kostitamisel: Siberis üldlevinud sööma-jooma sundimine polnud selles peres ega Kasekülas üldiselt tavaks. Teelaud aga kaeti meile pea igas peres.

\section{Pärimusekandjad ja traditsioonid, omaküla- raamatu mõju}

1993. aasta talvest olid Kaseküla eestlased, soojad sõbralikud inimesed, hästi meeles. Nüüd siis rõõmus jällenägemine. Püüdsin üles otsida kõik külas elavad 1993. aastal küsitletud, ka need, kelle juures käis tookord mõni teine ekspeditsioonigrupi liige. Nende inimeste küsitlemisel osutus otstarbekaks ka oma eelkäijast veidi rääkida. Varasemad uurijad teevad uutele n-ö tee lahti. Küsitlemine polnud taaskohtumisel kalli külalise seisuses olles sugugi lihtsam. Nii mõnigi kord arvati, et kõik on varemalt ära räägitud ning nüüd on aeg niisama jutuvestmiseks. Tegelikult suutsin ma oma vestluspartnereid korduvsalvestamise vajalikkuses siiski veenda. Seekord küsisin rohkem ka olustikulist ja eluloolist materjali, millele eelmisel korral piisavalt tähelepanu ei pööranud. 
Muidugi olid mõned varem küsitletutest nüüdseks igavikuteele läinud, mõned külast lahkunud, mõned tõsisemalt haigestunud. Küsitletute hulgas oli sedakorda ka noorema põlvkonna esindajaid ning meie eelmise külastuse ajal mujal elanuid (nt Eestis, Moldovas, Ukrainas) ning nüüdseks kodukülla naasnuid.

1993. aastaga võrreldes kuulsin nüüd traditsioonilist pärimust vähem: polnud enam tollasega võrreldavat ühist jutuvestmist ega kooslaulmist. Kõnekas on ehk fakt, et laulu sisse kasvanud suurlauliku Ida Mäetame Kasekülas elavast 11 lapsest oli nii mõnelgi emalt päritud ilus lauluhääl, kuid ei ühtki ema laulu. Seevastu jooksid külas ringi väikesed Roosid ja Helmid - vanaemade nimed on taas au sisse tõusnud.

Kasekülas, kus eesti keeles lugemis- ja kirjutamisoskus on suhteliselt paremini käes kui paljudes Omski oblasti külades, hoiti peredes raamatut "Seitse küla Siberis" aukohal ning need olid üsnagi kapsaks loetud. Minu saadetud raamatueksemplaridele lisaks oli neid külla toodud/saadetud ka Eestimaa sugulaste poolt, üks niisugune oli pühendusega ristitütrelt ristiisale. Kuna olin nüüd seitse raamatut oma seljakotis kaasa tassinud, sain üsna mitmele perele rõõmu valmistada. Minul raamatu koostajana oli edasine suhtlemine nende inimestega üsna hõlpus, kuid minu salvestamisest arvati üldiselt, et teen uut raamatut. Samas võidi ka arvata, et kõik on raamatus juba kirjas ning olemasolevale pole midagi lisada.

Sarja "Eesti asundused" raamatuid kasutatakse Siberi külades, kuhu need on jõudnud, sageli praktilise abivahendina: sealsed ravisõnad, ravivõtted, karja-ja põllupidamise tarkused leiavad taaskasutamist. Nii ka Kasekülas. Tegelikult pole selles midagi ebatavalist: samuti kasutatakse ka venekeelses ajakirjanduses ja kirjanduses leiduvaid põllupidamise ja arstimise õpetusi, trükitud ja käsikirjalisi laulukladesid, ristimis- ja matmiskaustikuid, kaitsekirju, esivanemate arstimissõnu jm. Teadmised on igal juhul vajalikud ning pole tähtis, kas need saadakse suusõnal edasiantuna või mõnest kirjalikust allikast.

Oma Siberi-ekspeditsioonidel olen pea alati kohalikke kalmistuid külastanud. Tookord aastate eest sai külast mõne kilomeetri kaugusel asuvale surnuaiale küll uhke saanisõit tehtud, kuid kasekolkas asuvast kalmuaiast siiski õiget pilti ei saanud. Nüüd avanes uus võimalus. Külarahvas suhtus meie surnuaeda minekusse veidi eba- 


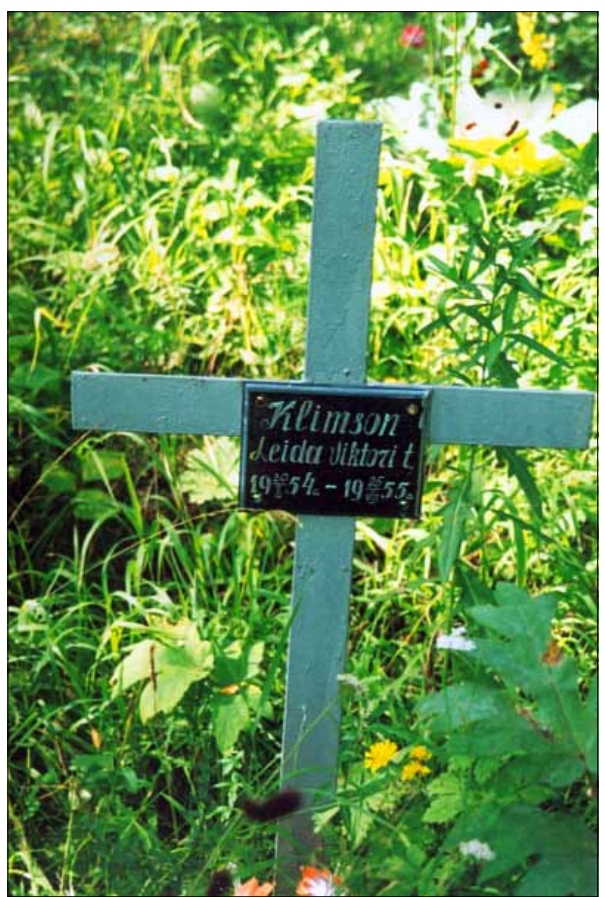

Eestlase haud Kaseküla surnuaias. Anu Korbi foto 2004.

levalt: see ju nii kaugel ja pole seal enam korda ega midagi. Tõepoolest pidime siin-seal murdunud puude ja oksarägastiku vahelt teed otsima, kuid leidsime eest ka hoolikalt korrastatud hauaplatse. Eriilmelistelt ristidelt-mälestuskividelt tuttavaid nimesid otsides torkas silma, et eestikeelsed hauakirjad olid siin märksa üldlevinumad kui mujal Siberi eestlaste juures, kuid vene traditsiooni järgides lisati ees- ja perekonnanime järele enamasti ka isanimi.

\section{Haridus- ja kultuurielu}

Kasekülas on keskkool, kus saavad haridust ka ümberkaudsete vene külade lapsed. Teadmisi hinnatakse kõrgelt ning lapsevanemad pingutavad, et oma võsukesi Tomski kõrgkoolidesse saata. Paraku tähendab kõrghariduse kättesaamine ka paljude noorte külast lahkumist. Mõned rõõmustavad erandid siiski on: Tomski ülikooli lõpetanud Alla Koot, kes oma diplomitöö Kaseküla eesti kogukonna ajaloost kirjutas, töötab nüüd kodukülas ajalooõpetajana.

Külas on oma muuseum, asutatud endise õpetaja Herman Reile poolt. Aastast 1992 on muuseum ajalooõpetaja Svetlana Leemani hoole all. Eesti keelt ta ei valda ning peab eesti materjalide osas keeleoskajailt abi paluma. Muuseumielu on igatahes edenenud: kui 1993. aasta talvel olid muuseumieksponaadid rõskes kütmata ruumis, siis nüüd kohendati parajasti muuseumi tarvis oma hoonet. Muu- 
seumiesemete (nt kangasteljed, kahemehe-saag, vokk, kannel, käsitööd) väljapaneku kõrval sai stendidelt infot ümberkaudsete eesti külade, nende asutajate ning hilisema eluolu kohta. Paraku seisis käimasoleva remondi tõttu suur osa materjalidest kastidesse pakituna.

Vene Föderatsioonis elavate väikerahvaste eneseteadvuse tõus ning sellega otseses seoses olev rahvuslike kuluuriseltside loomine Tomskis on Kaseküla eestlastele tugevat mõju avaldanud - Kasekülas loodi 1996. aastal Eesti kultuurikeskus. Tegemist pole küll ametlikult registreeritud rahvusühendusega (külarahvas polevat nõus maksma registreerimistasu), kuid Tomski Rahvaloomingu Keskuses on Kaseküla eestlased kirjas ning üks eestlane saab Vene riigilt eesti ajaloo ja pärimuse kogumise ning eesti kultuuri edendamise eest palka. Paraku pole sellele tööle vist kõige õigemat inimest leitud: osa kogutud materjalidest on tänaseks kadunud. Eesti kultuurikeskus koondab oma ümber vabatahtlikke entusiaste, nii lapsi kui vanu, kes üheskoos rahvakalendri tähtpäevi tähistavad, eesti laule ja tantse õpivad ning nendega oblasti folkloorifestivalidel ning muudelgi üritustel esinemas käivad. Kuna kuulajad on enamjaolt venekeelsed, tutvustatakse endid ja oma kultuuri vene keeles, lauldakse aga emakeeles.

Kuluurikeskuse algatus - eakate sünnipäevalaste üleslaulmine on aga tänaseks tekkinud erimeelsuste tõttu peaaegu vaibunud. Peamiselt majanduslikel põhjustel on hingusele läinud ka nelja aasta jooksul tegutsenud eesti keele ja kultuuri ring. Seevastu Kaseküla jaanipäeva tähistamine on laialt teada ning leidnud äramärkimist ka kohalikus turismiteatmikus.

\section{Kokkuvõtteks}

Pärimus on küll pidevas muutumises, kuid võõrsil asuva vähemusgrupi puhul, kellel emamaa tugi puudub ning kes igapäevase eluga toimetulemiseks järjest enam pingutama peab, on need muutused kindlasti kiiremad ja ulatuslikumad. Igapäevaselt eesti keelt rääkijate arv on Kasekülas viimase aastakümne jooksul tunduvalt vähenenud ka nende hulgas, kellel ladus keeleoskus olemas. Küla aktiivsemad eestlased on ohtu omakultuurile selgesti tajunud ning pingu- 
Anu Korb

tavad oma traditsioonide väärtustamise ja taaselustamise nimel, emakeele rolli ilmselt tajumata. Kas tulevikus saame rääkida Kaseküla venekeelsest eesti kogukonnast? 